\title{
Principle Elements of Curriculum in the Preschool Pattern of Montessori
}

\author{
Azizollah Baboli Bahmaee ${ }^{1}$, Zohreh Saadatmand ${ }^{2}$ \& Mohammad Hossein Yarmohammadian ${ }^{3}$ \\ ${ }^{1}$ Curriculum Planning, Isfahan (Khorasgan) Branch, Islamic Azad University, Isfahan, Iran \\ ${ }^{2}$ Department of Educational Sciences, Isfahan (Khorasgan) Branch, Islamic Azad University, Isfahan, Iran \\ ${ }^{3}$ Department of Educational Planning, Isfahan University of Medical Science, Isfahan, Iran \\ Correspondence: Azizollah Baboli Bahmaee, Curriculum Planning, Isfahan (Khorasgan) Branch, Islamic Azad \\ University, Isfahan, Iran. E-mail: baboliaziz@gmail.com
}

Received: June 22, 2015 Accepted: July 24, 2015 Online Published: December 29, 2015

doi:10.5539/ies.v9n1p148 URL: http://dx.doi.org/10.5539/ies.v9n1p148

\begin{abstract}
Montessori the physician and educational philosopher was probably one of the most prominent and famous education theorizer in the field of preschool education. Current research attempts to extract and clarify the major elements of curriculum by reliance on Montessori viewpoints. In this paper first the philosophical basics of preschool education from viewpoint of Montessori is discussed and then the key concepts of education in this theory is analyzed and the descriptive-analytical method is used for this analysis. Finally the fundamental elements of preschool curriculum are examined from its viewpoint. Montessori has considered the main objective of preschool education as development and growth of independence and acquiring individual and social skills and she proposed self-teaching, self-assessment and self-improvement for achieving this goal.
\end{abstract}

Keywords: Montessori, preschool education, planning, curriculum, self-study

\section{Introduction}

The twentieth century is known as the child century in comparison with past eras it is indeed as a golden age for children. As we move backward in terms of history, the level of caring children becomes lower and even the issue of annihilating and killing children is more noticeable. Children before seventieth century have sustained great deprivation and agonizing beating (Abdi, 2008). But now there is different approach toward childhood especially the preschool stage in terms of caring amount as well as the presented curriculum quality, because this period is highly sensitive time for children in term of physical and mental development and belief and language growth. Therefore it is essential that the curriculum of this era encompasses sufficient and necessary richness and dynamics and significant importance should be addressed to these programs (Torkman, 2003). During recent decades inscription of children in preschool courses has had increasing growth in majority of world countries. This ever-increasing growth is the natural outcome of emphasis of expert of education on the positive impact of spending such programs on social, cognitive and educational development in the children (Camilli et al., 2010). Current research attempts to extract and clarify the major elements of curriculum by reliance on Montessori viewpoints.

For examining the theory of curriculum in this educative viewpoint, it is necessary to understand the philosophical school and educative viewpoints of preschool education about objectives, methods and content of curriculum philosophical basics. Since curriculum theory is a set of statements related to each other that grant meaning to curriculum through determining the relation between elements of curriculum and conduction collecting process, therefor for identifying curriculum theory in preschool education, it is necessary to take into account following dimensions: educative ideals, perceived learning process, teacher's role, learner's role, perceived educational process and perceived lessons assessment. In this research one examines some of these elements.

\section{The Child from Montessori's Viewpoint (Montessori's Philosophy)}

Maria Montessori was born in Chiaravalle, one of Italy commune. After completion of preliminary educations she has studied medicine and has achieved to medicine doctorate degree at age of 26 years old (Mofidi, 2011). She was the first Italian woman who received medicine degree. After years of acquiring experience in medicine 
and teaching in the Rome University, she became enthusiastic to education. She developed and enhanced ideas and concepts through years of observation and conduction researches in the field of human, development, education and anthropology. She left her authentic academic job for realizing its idea (Lillard, 2013). Then she was missionized to lecture for Roma teachers for training mentally handicapped children. Thus she found a special interest toward training mentally retarded children and at age of 28 she undertook the management of governmental school of mentally disabled children. Simultaneously she engaged into a set of empirical psychology examinations about mentally retarded children and she performed it with collaboration of two French physicians named as Edward Seguin and Itard (Mofidi, 2011). She began her project in one of the poorest quarters in Italy, in the Yadera. Most of this city children were left in the street, when they parent was working for hours) and these children were illiterate and suffering from malnutrition. Montessori developed the most famous house of children by personal and governmental facilities in which most vulnerable children of Rome were cared and educated.

At the astonishment of all people majority of children grew socially and scientifically and thus the Montessori methods was approved throughout the Europe and was warmly confirmed and accepted by social groups. Since inauguration of first house of children in 1907 the theory and principles of Montessori remained permanent and became candidate of Nobel prize for three times. Nowadays there are more than 4000 Montessori schools in the USA and thousands of other schools in other countries around the world (Lillard, 2013). The essential objective of Montessori was motivating and fostering physical and sensational abilities through children activities and using designed and purposeful tools (Mofidi, 2011). It is worthy to mention that Montessori didn't consider the learning through play in such way that subsequently it has been set forth in twentieth century, but its learning tool was for encouraging individualism, not collective work. Nevertheless the collective work as giving homework was encouraged (Kul, 2012).

Montessori emphasized on teaching by senses and self-study. Its curriculum obtained such achievement that mentally handicapped children gave their examination together with normal students of Rome and this was an impressive achievement for Montessori. Though some admired and praised her work at the level of a miracle, but she engaged in study of reasons behind this event, why abnormal children can be equal even better than normal children within examinations (Curtis, 2001)? Montessori a young reformer in the field of education was in agreement with Froebel's opinions about education and she felt herself indebted to him. Consensus of Montessori and Froebel was related to their common catholic believes from one side and from other side to children clinical observations. The focus of Montessori was providing an environment that she considered it as its key theory about education from the birth onward. In her opinion the education is an aid for life and the education greatly influences on the children, because the child absorbs its environment, then it take everything from it and keeps it in the mind (Abbasi, 2003). Also the Montessori's viewpoint is based on comprehensive opinion of Dewey and believes that the whole of children personality should be addressed and the attention should be on the children's emotional and social development (Unisco, 2010).

Montessori's viewpoint about children is that the child is a creative human and can be flourished from the inside. She states that we find the pearl inside the shell, and the gold in the mountain, and the coal in the ground, but we are unaware from the child's soul hidden inside it. Montessori believes that child's growth is due to a vital force inside it that emerges in some periods with special sensitivity and then disappears at the same time, she notices that children has special developmental needs and have different need with respect to their normal peers. But she believed that all children (regardless from their being retarded or normal) have a lot of needs that can be addressed and met in the educational environment. She noticed that any child learn in its own manner and its own speed and on this basis, she innovated a comprehensive attitude that consider all child's need as a whole that was individually quite unique for every child (Habibi, 2011).

Her belief to freedom and its attention to child's nature reveal the Russo's beliefs and innovating educational tools by her shows the Frobel's believes susceptibility in its educative work. However its success and reputation caused that its schools have some branches in other countries as well (Mofidi, 2011) Montessori's educational method is more than 100 years that is used throughout the world and is recognized as the education basis of early childhood at contemporary age. Nevertheless this method basic is still remained as a mystery. What is Montessori's method? What is actually happening in classroom of this method? Montessori emphasized on developing independence growth and acquiring individual and social skills in the children as a principle objective of education. She considered the education as an aid for detecting inner powers of the child so that the child can have a positive impression toward curiosity, attention and concentration, spontaneity, ability to making decision, and personal discipline and sense of responsibility toward other people (Rumbush, 1999).

The goal of Montessori is supporting development of child's independence in terms of sensation-motion, 
intellectual, language and moral and some educations such as development and coordination of eye and hand or concentration training is more regarded in her viewpoint (Fuller et. al., 2007). Montessori's educational method leads in promotion of independence and self-confidence in children. In this method educators and teacher attempts to incorporate parent in their children's education. The objective of Montessori for minor children is to help in spontaneous development of personality in their intellectual, mental and physical dimensions and the trainer's duty is to understand the natural procedure of child's growth and provide some conditions through which the child can increase the speed of its development by gradual dominance on its environment (Abbasi, 2003).

\section{Heuristic Education or "Self-Study"}

Automatic education or "self-stud" is the pragmatic principle in the Montessori's educational system. In this educational system the curriculum is organized and planned in such manner that when the trainer is withdrawn and just monitor on activities and the children continue to educate themselves. This self-educating study is carried out by educational aid tools. Educational aid tools are consisted of twenty six different pieces that provide necessary facilities for training all senses except sense of taste and smell (Habibi, 2011). The classroom in the Montessori's method is so that allows to children to show all their talent during their activities. According to Montessori's viewpoint, the child acquires the things within observation, stimulation and exploration and they should not teach like elder children. The main key in Montessori's education is preparation of environment that includes internal and external space, developing the space and resources (Curtis, 2001). Therefore self-activity of children results in better and more permanent learning. And an adult or a teacher should place itself in the communication with the child's environment. Its task is preparing learning environment in an organized, arranged manner and equipped with adequate materials and tool and its only duty is to guide the child in such environment. The educational materials and tools should be preferably self-corrective that the child can obtain its own immediate feedback and carry on its attempts for learning (Kul, 2012).

Montessori emphasized on teaching by help of sense and self-teaching. Its curriculum had such achievement that the mentally retarded children under its teaching gave examination together with normal students of Rome students, and this was a phenomenal success for Montessori (Mofidi, 2011). At general one can say Montessori's tools ware so ranked accurately that each activity pursued a logical and arranged procedure and this ranking makes organizing thoughts possible in the children and teach problem solving skill in a clear and transparent manner through senses (Ongoren and Turcan, 2009; Kul, 2012; Mofidi, 2011). However, the objective of using educational tools in Montessori's technic is producing mental and personal independence in the children and hence the tools are characterized by simplicity, attraction, self-teaching and comprehensiveness.

\section{The Trainer in the Role of "Director" and the Student in the Role of "Active Seeker"}

The teacher in this attitude should place itself in the relation with the children's learning environment. Its duty is preparing the learning environment in an arranged and organized manner and its duty is only guiding children in such environment (Kul, 2012). The trainer that is called as director by Montessori is not constantly guiding and correcting children's activities, but the milieu is such that the child administrate naturally some guided and planned activities the interface of Montessori's method in education with other educational models is that in this method as long as the child has not learnt the manner of usage of a device from the trainer (director) is not allowed to use it (Curtis, 2001). The role of trainer in Montessori's classroom is different from other approaches and patterns. For example the independent activity of child forms near $80 \%$ of the work, while the teacher's work includes the other 20 percent. It is worth to mention that in the traditional education these percentages are reversing (Habibi, 2011).

If a child is not prepared for an experience, the teacher should wait so that the child itself organizes its inner life. It should provide a setting for child to engage in its activity spontaneously with minimum adult intervention and providing such environment for children is the objective of Montessori teachers (Kul, 2012). Another aspect of this procedure includes "normalization" of children. Montessori adjusts features and criteria of a normal child regarding flowing criteria: ability to conducting a task according to its nature. Freedom of observation, possibility of choosing personal activity and using its rhythm for performing thing. According to Montessori when a child fulfills its task he feels successful and satisfied and understands the importance of power of concentration. "Normalization" more than ever can be actualized within three to six years old (Curtis, 2001). In Montessori's philosophy any child is unique and matchless, therefore the development of any individual is different from the other one, and therefore any child is allowed to choose its favorite activities. At Montessori's schools the assistance desk is replaced with teacher's desk, therefore its method is titled as the method of free activity in a prepared environment (Al \& Sari, 1866-1871). 


\section{Productive Subject and Skill Content in Preschool Education}

It seems that the issue of educational content is a simple issue for the teacher in traditional educations, because the planning is what the students explains. This is related to trainer and based on what the student identifies as necessary, plans the content. But in education of skill and discourse problem design, the content of curriculum cannot be a gift and nor imposed. But it is organized expanded presentation of things that students are eager to know more about them. The Montessori's method was established on the basis of its theories about child development. She used to consider that the childhood is a highly sensitive stage in the human lifetime. In this stage the children can more easily learn skills and behaviors compared with other stages. Based on this notion she developed an environment addressing children needs in three essential and primarily eras of growth by using some special activities and tools (Mofidi, 2011).

\section{Self-Assessment and Self-Correction in Self-Teaching Method}

In this approach the assessment is for helping the individual to compare its situation with its own criteria and its trainer's criteria as well. The concept of examination and grade is meaningless in this classroom as well. The learning continues as long as the student acquires the considered competence and objective and felt satisfied from their activities. Since the Montessori's methods is established based on observation principle, the best learning in the children can take place through direct experience and exploration and detection form other side the freedmen of children for repeating an activity results in arrangement and concentration on a certain subject that Montessori considered it as the only correct principle in the education (Arce, 2000). If a child encounters to a defeat within learning during learning steps sequences, the teacher does not correct its mistake, but instead it ceases the lesson (Mofidi, 2011). It is worthy to mention that the Montessori's method is established on the basis of respect to the individual. Even most minor child is taught with respect that what is in its limit and appropriate for it and what is non adequate for it (Habibi, 2011). Montessori believed that children acquire most of the issues from their spontaneous activities and for the same reason she stressed greatly on preparation of educational environment. She stated that the children under six years old have not ability of elder children for using and understanding conversation or language and the elders should not use that type of language in the conversation that minor children fail to understand it (Curtis, 2001).

In this pattern the official examination for assessment are not used and the teachers assess the children's activities by regarding children's play that indeed is their works from viewpoint of Montessori. And recognizing children acquired skills and assessment of their achievements is carried out by observing and providing checklists by focusing of the learning procedure and stages of development of children (Habibi, 2011).

\section{Criticism and Examination}

The Montessori's pattern was applied at early years of twentieth century for mentally and physically disabled children at Rome, now it is more prevalent throughout USA rather than UK. Its diversity of thoughts is its strength as well as its weakness. It is strength because it turns numerous creative viewpoints from contemporary thoughts in a creative manner into one dynamic and challenging theory. And its weakness is that the same thing results in some special aspects of her writings seem highly highlighted in the expense of neglecting other parts. At first glance, it seems that the Montessori's educative philosophy belongs to mentally handicapped children in the world because she wants to enable humans to recreate the world by its own philosophy. Changing almost everything results in anxiety and defiant reaction among who profit from stability of current condition. She intended to redirect the educational system toward interest and needs of individuals that previously had no room in the educational system. Some part of Montessori's approach that was tremendously criticized was related to its viewpoint about playing and especially to imaginary playing. Montessori believed that the play is the child's work. But the only acceptable form for her was some type of playing that in adulthood setting had logistic aspect. For the same reason fantasy plays were not so acceptable and were insignificant because the child was far from reality. It is interesting that at subsequent years Kurien Hot took the same theory and said that within absurd and purposeless plays acquisition of children is insignificant or even is nonexistent. While within creative and heuristic games the match and education take place. Montessori and its followers were strongly defying fantasy game or magic legends. Because within magic stories and legends the beasts and monsters or the stories in which animals talk, the children are faced with false and distorted images from realities.

Montessori believed that by providing environment and adequate tools even if efficient teachers are not available the education of children is not disturbed. In that case, the teacher's skill for education method is less important. Some experts of new education knowledge disagree with this issue (with principle of need to educational preparation space). But lack of dynamics in the Montessori's theory especially with that developmental stage sequence was highly criticized. Because according to this theory there is no longer a room for spontaneous and 
dynamic education and the trainer has no opportunity to establish a new structure on the basis of experiences that the child brings from environment outside of the school. Furthermore, if one criticizes fairly, it is necessary to mention that Montessori has considered a special place for children in the educative sciences. When a lot of children around the world were educated among adults by collective educational system, she reminded their educational needs as an independent and self-thinking person. She knew children as active, energetic and dynamic creatures and she entirely defied this school of thinking that children are passive learners that should be saturated by mass of imposed information.

It is astonishing that theory of providing appropriate educational environment in which the child can be self-dynamic was subsequently excerpted by a lot of educational scholars who did not consider any place in their own thoughts for Montessori and at current time, works of Montessori is a base of many conducted activities in the field of child education (Curtis, 2001).

\section{Conclusion}

Montessori was one of prominent theorizers of child education; she set forth its educational ideas and implemented them in the practice. She have implemented most of its works about children's education and introduced her own curriculum to trainers of children and their parents, especially about training and educating children with intellectual disability in various countries whether theoretical or practically. Mixture of theory and practice made her ideas and measures as the most practical and prominent ones. Her philosophy of education were definitely susceptible form believes of Rousseau, Frobel and other naturalists such as Dewey, similarly her theories influenced on formation and organizing children education especially those with intellectual disability. Form one side her philosophy is humanistic and consider respect and value for the human as a creature with will-power who determine its own destiny and form other side it has a social viewpoint, in other word this creature with willpower has a social dimension and it should find its role in the society and make itself and its society as it wants.

Montessori set forth its theory about children's education in the form of books and discourses as well as implementing it in preschool classrooms in various countries. Its suggested method that was known as problem posing education was performed through dialog in cultural establishments. She was a critic of banking education and criticized the manner of accumulating information in the learners' mind, and believed for enhancing learner's awareness and ability one should guide them to freely thing to problem posed by the teacher that is set forth in the form of society tangible subjects and they may analysis these problem with an sharp and perceptive look and answer them. Montessori believes that classroom environment should be in conformity with children life, for the same reason tables, chairs, blackboard and all equipment of school should be appropriate for children viewpoint and their size and shape should be proportionate with children's size so that children don't encounter problem within using them, this helps in independence in usage of tools (Mofidi, 2011).

At general the dominant theory on curriculum of this pattern is established on developmentalist and allows the child in a free situation to reveals its developmental competence individually and without adults' intervention. In this approach the child deals with a broad range of materials and resources that facilitate the developmental flaw and helps the child to overcome the obstacles in the way of higher stage of development. The Montessori's education philosophy is established on this basis that the required times of repetition is different from child to child. Therefore there is necessity flexibility in required repetition amount in any skill at any day (Society, 2014). Montessori found out that children cannot acquire great deal of skills at a time. Some assignment is difficult for them because they lack some necessity motional skills. She made a special education for encountering such problems. She supported an educational system that can provide an environment for child to develop by its own speed.

\section{References}

Abbasi, A. (2003). Desing of optimal curriculum for kindergarten (Doctorate dissertation, Tehran, Teacher Training University).

Abdi, B. (2008). Social skills and behavioral problems of Iranian preschool children. Iran Psychologists Journal, 34-333.

Al, S., \& Sari, R. (1866-1871). A different perspective on education: Montessori and Montessori school architecture. Procedia-Social and Behavioral Sciences, 46.

Arce, E. (2000). Curriclum for young children: An introduction. Delmar thomson learning.

Camilli, G., Vargas, S., Ryan, S., \& Barnett, W. S. (2010). Meta-analysis of the effects of early education interventions on gognitive and social development. Teacher College Record, 112(3), 579-620. 
Curtis, A. (2001). Preschool Curriculum for children (Translation of Athari, M.). Tehran: Mehrab-e Qalam publications.

Fuller, B., Bridges, M., \& Pai, S. (2007). Standardized Childhood : the political and cultural struggle over early education (p. 385). Stanford Universit Press.

Habibi, P., \& Ahmadi, Q. A. (2011). Universal pattern of preschool education. Tehran, Srush publications.

Kul, V. (2012). Preschool curriculum (Translation of Mofidi, F.). Terhan: Samt publications.

Lillard, A. (2013). Playful learning and motessori education. American journal of Play, 5(2), 157-186.

Mofidi, F. (2011). Educational basics at preschool period. Tehran: Samt publications.

Ongoren, S., \& Turcan, A. (2009). The effectiveness of montessori education method in the acquisition of concept of geometrical shapees. word conference on educational sciences. Procedia social and behavioral sciences, 1.

Rumbush, N. (1999). Montessori's method: Stewardship of the spirit revision. Fall, 15(2), 79-82.

Society, A. M. (2014). Bank street and other pre-school, curriculums. Retrieved from $\mathrm{http}$ ://amshq.org/Montesori-educaiton/introduction-to-mintessori

Torkman, M. (2003). Learning language basics, for pre-school educational centers. Tehran: School publications.

Unisco. (2010). What is your image of the child? Unesco policy Brief on early childhood, January-March 2010. Retrieved from http://www.unesco.org/en.early-childhood/unesco-policry-brief-on-childood

\section{Copyrights}

Copyright for this article is retained by the author(s), with first publication rights granted to the journal.

This is an open-access article distributed under the terms and conditions of the Creative Commons Attribution license (http://creativecommons.org/licenses/by/3.0/). 